\title{
Childhood adversities as risk factors for onset and persistence of suicidal behaviour
}

Ronny Bruffaerts, Koen Demyttenaere, Guilherme Borges, Josep Maria Haro, Wai Tat Chiu, Irving Hwang, Elie G. Karam, Ronald C. Kessler, Nancy Sampson, Jordi Alonso, Laura Helena Andrade, Matthias Angermeyer, Corina Benjet, Evelyn Bromet, Giovanni de Girolamo, Ron de Graaf, Silvia Florescu, Oye Gureje, Itsuko Horiguchi, Chiyi Hu, Viviane Kovess, Daphna Levinson, Jose Posada-Villa, Rajesh Sagar, Kate Scott, Adley Tsang, Svetlozar M. Vassilev, David R. Williams and Matthew K. Nock

\section{Background}

Suicide is a leading cause of death worldwide, but the precise effect of childhood adversities as risk factors for the onset and persistence of suicidal behaviour (suicide ideation, plans and attempts) are not well understood.

\section{Aims}

To examine the associations between childhood adversities as risk factors for the onset and persistence of suicidal behaviour across 21 countries worldwide.

\section{Method}

Respondents from nationally representative samples

$(n=55299)$ were interviewed regarding childhood adversities that occurred before the age of 18 years and lifetime suicidal behaviour.

\section{Results}

Childhood adversities were associated with an increased risk of suicide attempt and ideation in both bivariate and multivariate models (odds ratio range 1.2-5.7). The risk increased with the number of adversities experienced, but at a decreasing rate. Sexual and physical abuse were consistently the strongest risk factors for both the onset and persistence of suicidal behaviour, especially during adolescence. Associations remained similar after additional adjustment for respondents' lifetime mental disorder status.

\section{Conclusions}

Childhood adversities (especially intrusive or aggressive adversities) are powerful predictors of the onset and persistence of suicidal behaviours.

\section{Declaration of interest}

R.C.K. has been a consultant for GlaxoSmithKline, Kaiser Permanente, Pfizer, Sanofi-Aventis, Shire Pharmaceuticals, and Wyeth-Ayerst, has served on advisory boards for Eli Lilly \& Company and Wyeth-Ayerst, and has had research support for his epidemiological studies from Bristol-Myers Squibb, Eli Lilly \& Company, GlaxoSmithKline, Johnson \& Johnson Pharmaceuticals, Ortho-McNeil Pharmaceuticals, Pfizer and Sanofi-Aventis.
Suicide is one of the leading causes of death worldwide but the aetiology of suicide is still not well understood. Mental disorders are important risk factors for suicidal behaviour ${ }^{1-3}$ but most people with mental disorders do not manifest suicidal behaviour. ${ }^{4}$ There is strong evidence that environmental or experiential factors also contribute to the onset and persistence of suicidal behaviours, ${ }^{5,6}$ and that they have a stronger association with negative mental health outcomes than currently known genetic factors. ${ }^{7}$ There is consistent evidence showing a significant association between reported childhood adversities and suicidality in adulthood. ${ }^{8-10}$ However, childhood adversities have received much less scientific attention than mental disorders or genetic factors.

Existing research has been limited in four ways. First, we found no multinational population-based studies investigating the association between childhood adversities and suicidal behaviour. Second, population-based and clinical studies often assessed a relatively limited number of childhood adversities. The effect of a broad range of adversities on suicidal behaviours have not been investigated yet. Third, in general, simple models have been tested that do not take into account both the type of adversities and the effect of accumulation of multiple adversities. Further, prior studies have not carefully examined whether the effect of child adversities on suicidal behaviour differs over the course of the lifespan, despite earlier evidence for such an effect. ${ }^{11}$ Fourth, virtually all prior studies have shown that adversities are associated with subsequent onset of suicidal behaviour, but no studies of which we are aware have investigated the extent to which childhood adversities might predict the transition from suicide ideation to suicide attempt or the persistence of suicidal behaviour over time.

Here we use data from the World Mental Health surveys, general population surveys using the latest structured psychiatric interviews generating DSM-IV ${ }^{12}$ disorders for mental disorders, a broad range of childhood adversities, and a whole set of suicidality-related variables. The current study was designed to address each of these limitations by conducting comprehensive cross-national analyses of the associations between a range of childhood adversities and subsequent suicidal behaviour. We aimed to investigate: the associations between childhood adversities and multiple forms of suicidal behaviour, with separate models estimating both the unique and overall effects of each type of adversity; the extent to which the associations differ over the course of the respondents' lifespan; and the associations between childhood adversities and the persistence of suicidal behaviour.

\section{Method}

\section{Respondent samples}

The World Mental Health surveys were carried out in 21 countries in: Africa (Nigeria, South Africa); the Americas (Brazil, Colombia, Mexico, USA), Asia and the Pacific (India, Japan, New Zealand, Beijing, Shanghai, and Shenzhen in the People's Republic of 
China), Europe (Belgium, Bulgaria, France, Germany, Italy, The Netherlands, Romania, Spain, Ukraine); and the Middle East (Israel, Lebanon). The World Bank ${ }^{13}$ classifies Colombia, India, Nigeria, China and Ukraine as low- and lower-middle-income countries; Brazil, Bulgaria, Lebanon, Mexico, Romania and South Africa as upper-middle-income countries; and all other survey countries as high-income countries. Respondents were selected in most World Mental Health countries using a stratified multistage clustered-area probability sampling strategy. The total sample size was 109377 , with individual country sample sizes ranging from 2357 in Romania to 12790 in New Zealand. The weighted average response rate across all countries was $73.3 \%$.

\section{Procedures}

All surveys were conducted face to face by trained lay interviewers. Informed consent was obtained from all participants. During interviews, all respondents provided sociodemographic and core diagnostic information, including history of suicidal behaviours. Internal subsampling was used to reduce respondent burden and average interview time and cost by dividing the interview into two parts. Part 1 included the core diagnostic assessment of mental disorders. Part 2 included additional information relevant to a wide range of survey aims, including assessment of childhood adversities. All respondents completed Part 1. All Part 1 respondents who met criteria for any lifetime mental disorder and a probability sample of other respondents were administered Part 2. Part 2 respondents were weighted by the inverse of their probability of selection for Part 2 of the interview to adjust for differential sampling. Analyses in this article were based on the weighted Part 2 subsample $(n=55299)$. Additional weights were used to adjust for differential probabilities of selection within households, to adjust for non-response, and to match the samples to population sociodemographic distributions. More details on these procedures can be found elsewhere. ${ }^{14-16}$

\section{Suicidal behaviour}

Suicidal behaviours were assessed using the Composite International Diagnostic Interview-3.0 (CIDI-3.0) suicidality module. ${ }^{17}$ This module includes an assessment of the lifetime occurrence and age at onset of suicide ideation, plan and attempt. Consistent with our aims, five dated lifetime history suicide outcomes were considered in this study: suicide ideation in the total sample; suicide attempt in the total sample; suicide plan among ideators; suicide attempt among ideators with a plan (planned attempt); and suicide attempt among ideators in the absence of a plan (unplanned attempt).

\section{Childhood adversities}

The following childhood adversities were included in the present report: physical abuse, sexual abuse, neglect, parental death, parent divorce, other parental loss, family violence, physical illness and financial adversity before the age of 18 (see online supplement). We looked at childhood adversities occurring in the context of the family only and not all possible childhood adversities such as natural disasters or exposure to war.

\section{Statistical analysis}

Discrete-time survival models with person-year as the unit of analysis $^{18}$ were used to investigate the association between childhood adversities and suicidal behaviour. Childhood adversities were treated as starting at age 4. Both bivariate (in which only one adversity was considered at a time) and multivariate analyses (in which all adversities were considered simultaneously) were performed. Two types of multivariate models were tested: one that included all types of childhood adversities simultaneously (multivariate additive), and one that included type and number of adversities experienced by each respondent as dummy variables (multivariate interactive). The latter was the best-fitting model. Interactions between each adversity and respondent stage in the life course (13-19 years, 20-29 years, 30+ years) and the extent to which each adversity predicts early-, middle- and late-onset suicidal behaviour were also tested. Finally, we investigated the association between childhood adversities and the persistence of suicidal behaviour over time, using backward recurrence models. ${ }^{19}$ We predicted the most recent suicide attempt among respondents who have ever attempted suicide by looking back in time from the year of interview.

In all analyses, coefficients and standard errors were exponentiated for ease of interpretation and are reported as odds ratios (ORs) with 95\% CIs. Standard errors were estimated with the Taylor series method ${ }^{20}$ using SUDAAN (Software for Survey Data Analysis, version 8.1 on UNIX-Solario/SUN OS, www. rti.org/SUDAAN) to adjust for weighting and clustering. Multivariate significance was evaluated with Wald $\chi^{2}$-tests based on design-corrected coefficient variance-covariance matrices. Associations between adversities and suicide outcomes were adjusted for country differences, gender, age, educational attainment, marriage, interactions between demographics and lifecourse (person-year intervals of 13-19, 20-29, 30+ years), parental psychopathology (major depressive episode, generalised anxiety disorder, panic disorder, substance use disorder, antisocial personality disorder and parental suicidal behaviour). We tested the extent to which associations were mediated by respondents' lifetime mental disorders (mood disorders (major depressive episode, dysthymia, bipolar disorder), anxiety disorders (panic disorder, agoraphobia without panic, generalised anxiety disorder, specific phobia, social phobia, post-traumatic stress disorder, adult separation anxiety disorder), externalising disorders (attention-deficit hyperactivity disorder, oppositional-defiant disorder, conduct disorder, intermittent explosive disorder), and substance use disorders (alcohol misuse or dependence, illicit drug use or dependence)). Disorders were assessed using the CIDI-3.0. ${ }^{17}$ As there may be gender differences in the association between childhood adversities and suicidal behaviour, we additionally tested the interactions between gender and each of the childhood adversities. All significance tests were evaluated using 0.05-level two-sided tests.

\section{Results}

\section{Childhood adversities and suicidal behaviour}

Childhood adversities were common, with ranges between 2.0 and $12.2 \%$. Most common were the death of a parent $(12.2 \%)$, physical abuse $(8.0 \%)$, and family violence $(6.9 \%)$. Approximately $6 \%$ of respondents reported parent divorce, and a similar proportion reported any other parental loss. Lifetime suicide attempt and ideation were reported by $2.7 \%(n=2831)$ and $9.4 \%(n=8382)$ of the respondents respectively. Among ideators, $34.5 \%(n=3324)$ developed a suicide plan, $55.2 \%$ of those with a plan $(n=1894)$ made a suicide attempt, $15.1 \%$ of those without a plan $(n=937)$ made an attempt ('unplanned attempt'). Among those with a history of suicide attempt, nearly a third (29.3\%) reported physical abuse, about one in four (24.8\%) family violence, and one in six (14.5\%) sexual abuse. Most adversities were in the $6.0-29.3 \%$ range among those with a lifetime suicide attempt (Table 1). 
Table 1 Prevalence of childhood adversities among respondents with suicidal behaviours

\begin{tabular}{|c|c|c|c|c|c|}
\hline \multirow[b]{2}{*}{ Type of adversity } & \multicolumn{5}{|c|}{ \% (s.e.) } \\
\hline & $\begin{array}{l}\text { Lifetime } \\
\text { attempt }\end{array}$ & $\begin{array}{l}\text { Lifetime } \\
\text { ideation }\end{array}$ & $\begin{array}{l}\text { Lifetime plan among } \\
\text { lifetime ideators }\end{array}$ & $\begin{array}{l}\text { Lifetime attempt among } \\
\text { those with a lifetime plan }\end{array}$ & $\begin{array}{l}\text { Lifetime attempt among } \\
\text { those without a plan }\end{array}$ \\
\hline Physical abuse & $29.3(1.2)$ & $20.6(0.6)$ & $25.4(1.0)$ & $29.7(1.5)$ & $26.8(1.8)$ \\
\hline Sexual abuse & $14.5(0.8)$ & $8.5(0.3)$ & $12.3(0.7)$ & $15.4(1.0)$ & $12.3(1.1)$ \\
\hline Neglect & $19.3(0.9)$ & $13.1(0.5)$ & $17.5(0.8)$ & $20.8(1.2)$ & $15.4(1.6)$ \\
\hline Parent died & $16.1(0.8)$ & $14.2(0.5)$ & $15.0(0.8)$ & $16.6(1.1)$ & $15.6(1.7)$ \\
\hline Parent divorced & $15.6(1.0)$ & $11.7(0.5)$ & $11.9(0.7)$ & $14.7(1.2)$ & $17.8(1.8)$ \\
\hline Other parent loss & $11.2(0.7)$ & $8.4(0.4)$ & $8.9(0.7)$ & $10.3(0.9)$ & $12.9(1.3)$ \\
\hline Family violence & $24.8(1.1)$ & $17.6(0.5)$ & $21.5(0.9)$ & $23.3(1.2)$ & $25.4(1.9)$ \\
\hline Physical illness & $8.7(0.7)$ & $6.6(0.3)$ & $7.9(0.6)$ & $9.2(0.9)$ & $8.2(1.2)$ \\
\hline Financial adversity & $6.0(0.5)$ & $4.8(0.3)$ & $4.7(0.4)$ & $5.5(0.6)$ & $7.4(0.9)$ \\
\hline
\end{tabular}

\section{Associations between type of adversities and onset of suicidality}

In bivariate models (Table 2), eight out of nine adversities were associated with increased odds of a suicide attempt $(\mathrm{OR}=1.3$ 5.7) and ideation $(\mathrm{OR}=1.2-3.4)$. Physical and sexual abuse consistently yielded the highest odds for both suicide attempt and ideation ( $\mathrm{OR}=3.7-5.7$ and $\mathrm{OR}=2.7-3.4$ respectively). The other suicidal behaviours were most consistently predicted by sexual abuse $(\mathrm{OR}=1.3-1.4)$. In multivariate additive models (Table 2), odds ratios decreased but none lost their statistical significance. Specific adversities that yielded odds ratios of 2 or higher were physical abuse, sexual abuse and neglect. In general, adversities had stronger associations with attempt and ideation than with suicide plans and planned or unplanned attempts.

\section{Associations between number of adversities and onset of suicidality}

We found a strong dose-response relationship between the number of reported adversities and four of the five suicide outcomes (i.e. lifetime attempt, ideation, attempt among those with a plan, and unplanned attempt) (Table 3).

\section{Associations between type and number of adversities and onset of suicidal behaviour}

The multivariate interactive models shown in Table 2 revealed that all nine adversities are significantly associated with suicide attempt $(\mathrm{OR}=1.3-4.6$, median $\mathrm{OR}=2.2)$ and ideation $(\mathrm{OR}=1.3-3.4$, median $\mathrm{OR}=1.7)$. The odds ratios for types in the multivariate interactive model are higher than for types in the multivariate additive model. This is logical since the additive model does not allow for sub-additive effects of number of childhood adversities, and so leads to an underestimation of the effects of individual childhood adversities. Again, sexual and physical abuse were most predictive $(\mathrm{OR}=2.7-4.6)$. Adversities do not have strong predictive values for plan or attempt among respondents with suicide ideation; of the 27 odds ratios investigated, only 3 were significant. Even after adjustments for respondents' lifetime mental disorder, the direction and strength of the associations remained stable. For example, eight out of nine adversities remained significantly associated with both suicide attempt $(\mathrm{OR}=1.7-3.1$, median $\mathrm{OR}=2.1)$ and all nine adversities were significantly associated with suicide ideation $(\mathrm{OR}=1.3-2.6$, median $\mathrm{OR}=1.7$ ) after adjustments for respondent's mental disorder (online Table DS1). This suggests only a minor impact of mental disorders in the association between childhood adversity and suicidal behaviour.
The odds ratios associated with the number of adversities become increasingly smaller (and below 1.0) with increasing number of adversities for attempt and ideation (Table 3). This indicates significant sub-additive interactions among adversities; that is, the joint effects of multiple adversities are significantly less than the product of the odds ratios associated with the individual adversities.

\section{Associations between adversities with onset of suicidal behaviour across the lifespan}

Interestingly, childhood adversities had the strongest associations with attempt in childhood (median significant $\mathrm{OR}=3.8$ ), decreasing during teen years (median significant $\mathrm{OR}=2.5$ ) and young adulthood (median significant $\mathrm{OR}=2.0$ ), and increasing in later adulthood (median significant $\mathrm{OR}=2.3$ ) (Table 4). Sexual abuse was an especially strong predictor of an attempt in young people (Table 4; more detailed results on the other suicidal behaviours are available from the author on request). Specifically, a history of childhood sexual abuse was associated with a 10.9-fold increase in the odds of an attempt between the ages of 4-12 years, a 6.1-fold increase in the odds of an attempt between the ages of 13 and 19 years, and 2.9-fold increase among those between the ages of 20 and 29 years. Further, adversities remained predictive of suicide attempt and ideation throughout the lifespan, but they were less predictive of which ideators develop a lifetime plan or make a planned or unplanned attempt (Table 4). Odds ratios for these associations are considerably smaller in magnitude, and there is no single adversity that stands out as a consistent predictor. Additional analyses that tested the interaction effects between gender and childhood adversities and their association with suicidal behaviours revealed that there were no such effects (online Table DS2). Of the 36 associations investigated, only 1 was significant.

\section{Associations between childhood adversities and persistence of suicidal behaviour}

Adversities involving physical abuse, sexual abuse, parental loss, family violence and physical illness were significantly but modestly associated with persistence of a broad range of suicidal behaviours (especially attempt among ideators, ideation and plan among ideators) in bivariate analyses $(\mathrm{OR}=1.2-2.0)$ (data available from the author on request). The number of adversities also generated significant effects, with exposure to multiple adversities being predictive of ideation $(\mathrm{OR}=1.2-1.4)$ and plan $(\mathrm{OR}=1.4-1.7)$, but not of planned or unplanned attempt. After adjusting for respondents' lifetime mental disorders, the strength of the 

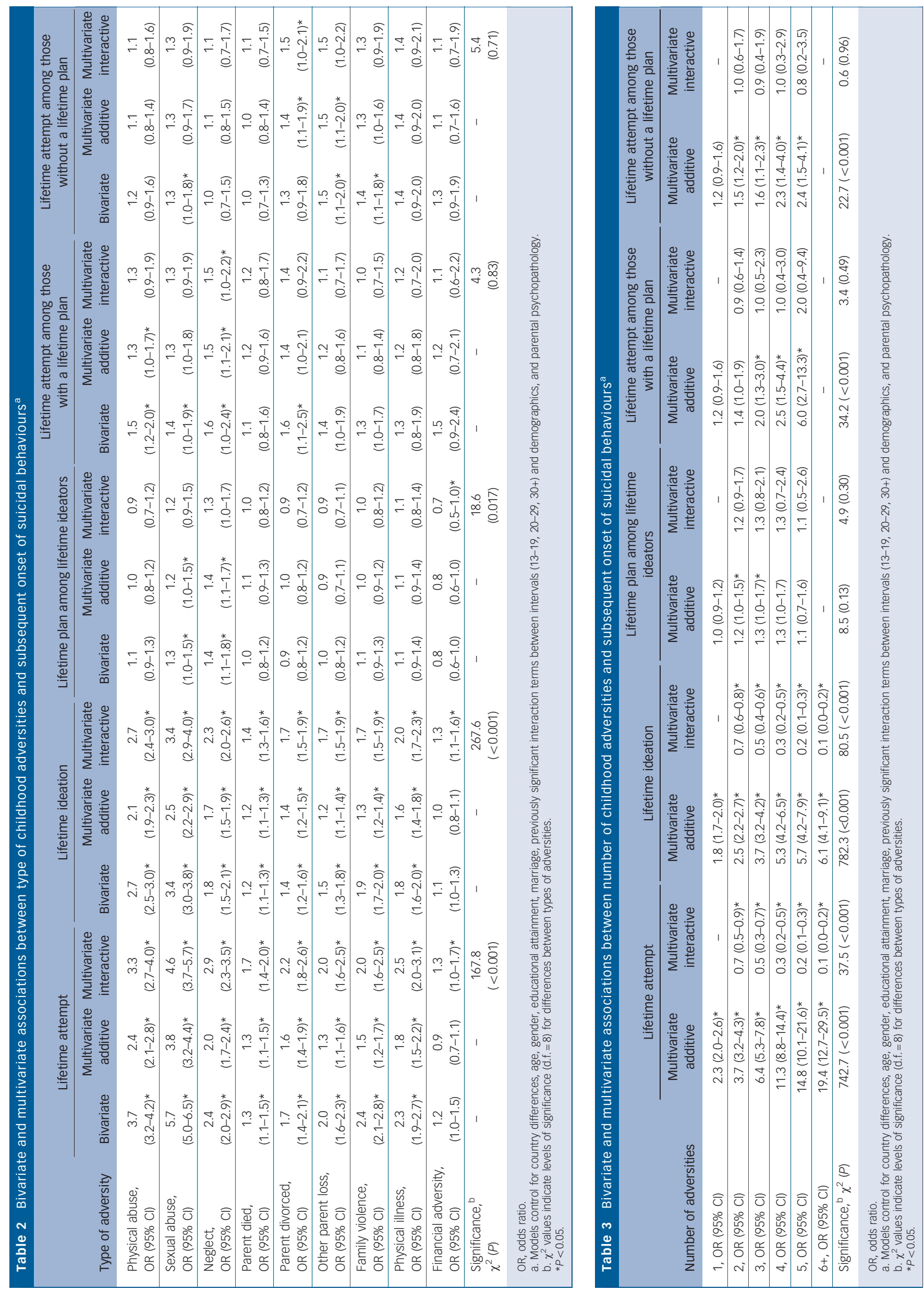
Table 4 Multivariate associations between type and number of childhood adversities with subsequent onset of suicide attempt across the lifespan ${ }^{\mathrm{a}}$

Lifetime attempt during Lifetime attempt during Lifetime attempt during Lifetime attempt during later childhood years, age 4-12 teen years, age 13-19 young adulthood, age 20-29 adulthood, age 29+

Type of adversity

Physical abuse, OR $(95 \% \mathrm{Cl})$ Sexual abuse, OR $(95 \% \mathrm{Cl})$ Neglect, OR $(95 \% \mathrm{Cl})$

Parent death, OR (95\% Cl) Parent divorce, OR $(95 \% \mathrm{Cl})$ Other parent loss, OR $(95 \% \mathrm{Cl})$ Family violence, OR (95\% Cl) Physical illness, OR (95\% Cl) Financial adversity, OR (95\% Cl) Significance, ${ }^{\mathrm{b}} \chi^{2}(P)$ Number of adversities

2 adversities, OR (95\% Cl)

3 adversities, OR $(95 \% \mathrm{Cl})$

4 adversities, OR $(95 \% \mathrm{Cl})$ 5 adversities, OR $(95 \% \mathrm{Cl})$ 6+ adversities, OR (95\% Cl) Significance, ${ }^{\mathrm{b}} \chi^{2}(P)$

$6.3(3.1-13.0)^{\star}$
$10.9(5.0-23.7)^{\star}$
$4.6(1.5-14.1)^{\star}$
$2.2(1.0-4.8)^{\star}$
$3.2(1.5-6.9)^{\star}$
$4.2(2.0-8.8)^{\star}$
$2.6(1.2-5.8)^{\star}$
$3.3(1.6-6.8)^{\star}$
$1.4(0.6-2.9)$
$48.2(<0.001)$

$4.1(3.0-5.6)^{\star}$
$6.1(4.4-8.4)^{\star}$
$2.7(1.9-3.7)^{\star}$
$1.6(1.2-2.2)^{\star}$
$2.2(1.6-2.9)^{\star}$
$2.3(1.6-3.3)^{\star}$
$2.2(1.6-3.1)^{\star}$
$3.0(2.0-4.3)^{\star}$
$1.4(0.9-2.1)$
$117.9(<0.001)$

$$
\begin{gathered}
2.5(1.8-3.5)^{\star} \\
2.9(1.9-4.3)^{\star} \\
2.1(1.4-3.0)^{\star} \\
1.5(1.1-2.0)^{\star} \\
2.0(1.4-2.8)^{\star} \\
1.3(0.9-1.9) \\
1.6(1.1-2.3)^{\star} \\
1.9(1.2-3.0)^{\star} \\
1.0(0.6-1.6) \\
47.3(<0.001)
\end{gathered}
$$

$2.1(1.4-3.0)^{*} \quad 3.8(2.7-5.4)^{*}$

$1.5(1.1-2.0)^{*} \quad 1.7(1.3-2.3)^{*}$

$2.0(1.4-2.8)^{*} \quad 2.0(1.3-3.1)^{*}$

$1.3(0.9-1.9) \quad 2.0(1.3-2.9)^{*}$

$1.6(1.1-2.3)^{*} \quad 2.1(1.5-3.1)^{*}$

$1.9(1.2-3.0)^{*} \quad 2.4(1.5-3.7)^{*}$

$1.0(0.6-1.6) \quad 1.5(0.8-2.7)$

$30.7(<0.001)$

$\begin{array}{cc}0.5(0.2-1.4) & 0.6(0.4-0.8)^{*} \\ 0.3(0.1-1.4) & 0.3(0.2-0.6)^{*} \\ 0.2(0.0-1.3) & 0.2(0.1-0.5)^{\star} \\ 0.1(0.0-0.9)^{\star} & 0.1(0.0-0.4)^{*} \\ 0.0(0.0-0.8)^{\star} & 0.0(0.0-0.2)^{*} \\ 7.7(\mathrm{~ns}) & 21.7(<0.001)\end{array}$

$0.7(0.5-1.1)$

$0.5(0.2-1.0)^{*}$

$0.3(0.1-0.7)^{*}$

$0.1(0.0-0.3)^{*}$

$0.0(0.0-0.1)^{*}$ $25.9(<0.001)$

OR, odds ratio; ns, not significant.

a. Models control for country differences, age, gender, educational attainment, marriage, previously significant interaction terms between intervals (13-19, 20-29, 30+) and demographics, and parental psychopathology.

b. $\chi^{2}$ values indicate levels of significance (d.f. $\left.=8\right)$ for differences between types of adversities.

\begin{tabular}{|c|c|c|c|c|c|}
\hline & $\begin{array}{l}\text { Lifetime } \\
\text { attempt }\end{array}$ & $\begin{array}{l}\text { Lifetime } \\
\text { ideation }\end{array}$ & $\begin{array}{l}\text { Lifetime plan among } \\
\text { respondents with } \\
\text { lifetime ideation }\end{array}$ & $\begin{array}{c}\text { Lifetime attempt } \\
\text { among ideators with } \\
\text { lifetime plan }\end{array}$ & $\begin{array}{c}\text { Lifetime plan among } \\
\text { ideators without } \\
\text { lifetime plan }\end{array}$ \\
\hline \multicolumn{6}{|l|}{ Type of adversity } \\
\hline Physical abuse, OR (95\% Cl) & $1.5(1.1-2.3)^{\star}$ & $1.2(1.0-1.4)$ & $1.4(1.1-1.9)^{*}$ & $1.5(1.0-2.3)$ & $2.3(1.1-4.8)^{*}$ \\
\hline Sexual abuse, OR (95\% Cl) & $1.6(1.1-2.3)^{\star}$ & $1.2(1.0-1.4)$ & $1.4(1.1-1.9)^{*}$ & $1.8(1.2-2.8)^{*}$ & $1.3(0.6-3.0)$ \\
\hline Neglect, OR (95\% Cl) & $1.0(0.7-1.4)$ & $1.0(0.9-1.2)$ & $1.0(0.8-1.4)$ & $1.0(0.6-1.5)$ & $1.3(0.6-2.5)$ \\
\hline Parent death, OR (95\% Cl) & $0.7(0.4-1.0)$ & $0.9(0.8-1.1)$ & $1.1(0.8-1.4)$ & $0.7(0.5-1.1)$ & $0.7(0.3-1.6)$ \\
\hline Parent divorce, OR (95\% Cl) & $0.8(0.5-1.1)$ & $0.9(0.7-1.1)$ & $0.9(0.7-1.3)$ & $0.8(0.5-1.2)$ & $0.9(0.4-1.7)$ \\
\hline Other parent loss, OR (95\% Cl) & $0.8(0.5-1.3)$ & $1.2(1.0-1.5)$ & $1.2(0.9-1.7)$ & $0.8(0.5-1.4)$ & $1.2(0.6-2.5)$ \\
\hline Family violence, OR $(95 \% \mathrm{Cl})$ & $1.0(0.7-1.6)$ & $1.0(0.8-1.2)$ & $1.2(0.9-1.6)$ & $1.2(0.8-1.8)$ & $1.2(0.6-2.4)$ \\
\hline Physical illness, OR (95\% Cl) & $1.3(0.8-2.1)$ & $1.0(0.8-1.2)$ & $0.9(0.6-1.3)$ & $1.4(0.8-2.5)$ & $1.3(0.7-2.5)$ \\
\hline Financial adversity, OR (95\% Cl) & $1.0(0.6-1.6)$ & $1.0(0.8-1.4)$ & $0.9(0.5-1.5)$ & $1.0(0.5-1.9)$ & $1.5(0.5-4.1)$ \\
\hline Significance, ${ }^{b} \chi^{2}(P)$ & $49.3(<0.05)$ & $17.1(<0.05)$ & $15.8(<0.05)$ & $31.9(<0.05)$ & 11.9 (ns) \\
\hline \multicolumn{6}{|l|}{ Number of adversities } \\
\hline 2 adversities, OR (95\% Cl) & $1.1(0.7-1.8)$ & $1.1(0.9-1.4)$ & $1.1(0.7-1.5)$ & $1.0(0.6-1.9)$ & $0.8(0.4-1.9)$ \\
\hline 3 adversities, OR (95\% Cl) & $0.9(0.4-1.9)$ & $1.1(0.7-1.6)$ & $0.9(0.5-1.6)$ & $0.8(0.3-1.9)$ & $0.5(0.1-2.2)$ \\
\hline 4 adversities, OR (95\% Cl) & $1.0(0.3-3.1)$ & $1.2(0.7-2.0)$ & $0.9(0.4-2.0)$ & $0.8(0.2-3.1)$ & $0.5(0.1-3.2)$ \\
\hline 5 adversities, OR (95\% Cl) & $0.6(0.1-2.5)$ & $0.9(0.5-1.8)$ & $0.9(0.3-2.6)$ & $0.6(0.1-3.1)$ & $0.4(0.0-5.3)$ \\
\hline 6+ adversities, OR (95\% Cl) & $1.4(0.2-8.8)$ & $0.9(0.3-2.3)$ & - & - & - \\
\hline Significance, ${ }^{b} \chi^{2}(P)$ & 8.8 (ns) & 3.9 (ns) & 1.7 (ns) & 2.4 (ns) & 1.0 (ns) \\
\hline
\end{tabular}

$* P<0.05$
$\chi^{2}$.

associations remained similar (data available from the author on request). These associations were most relevant in younger respondents (data available from the author on request). In multivariate interactive analyses (Table 5), although the strength of the significant odds ratios was similar, the type of adversity meaningfully vary in their associations with persistence of suicidal behaviours as four out of five tests were statistically significant. Sexual and physical abuse were the only adversities yielding a significant association with persistence of nearly all suicidal behaviours $(\mathrm{ORs}=1.4-2.3)$. We also tested interaction effects between gender and childhood adversities and their association with persistence of suicidal behaviours but we could not find evidence for such effects (online Table DS3).

\section{Discussion}

\section{Limitations}

These results should be interpreted in light of the following limitations. First, recall bias may affect the accuracy of the 
adversity recall; rates of forgetting to report abusive experiences have been estimated to be in the $20-33 \%$ range $^{21}$ but without consistent evidence for false-positive reports. ${ }^{22}$ Second, respondents who did not speak the main language(s) of the country sufficiently, those institutionalised, and those without a fixed address were not included in the present study. It cannot be ruled out that these groups of people differed in the association between childhood adversities and suicidal behaviours. Third, the assessment of persistence is an approximation of the duration of the suicidal episode and the risk of recurrence among those with a history of past suicidal episodes. Because the World Mental Health surveys are cross-sectional surveys, it was not possible to calculate persistence of suicidality directly from complete information of the duration of incident episodes, time to recurrence after offset of incident episodes, duration of second episodes, or time to recurrence of third episodes after offset of second episodes. Fourth, although the range of childhood adversities assessed here is larger than in most previous studies, it is far from exhaustive and did not assess the severity, duration, or sequencing of any of these adversities. Fifth, although our results were controlled for country differences, we cannot rule out that there were specific cross-cultural differences in the prevalence and meaning of the suicidal behaviours. ${ }^{23,24}$

\section{Main findings}

We found that exposure to multiple adversities consistently predicted suicidal behaviours. Our findings extend earlier work $^{11,25,26}$ on the graded relationship between the number of adversities and lifetime suicide attempts by replicating the association with suicide attempt and by documenting the association between childhood adversities and a more carefully defined range of suicidal behaviours. Some of the associations we found were different from those in previous reports. This could be as a result of methodological differences; for instance, the sample used by Dube and colleagues ${ }^{25}$ consisted of participants from a large health maintenance organisation and not the general population. This leaves open the possibility that associations between adversities and suicide attempt could be different in people seeking help compared with the general population. Despite the significant dose-response relationship, however, the odds ratio between number of adversities and attempt and ideation become increasingly smaller. This points to a decrease in the predictive power when the number of experienced adversities gets larger, suggesting a ceiling effect of the impact of childhood adversities. We extend the existing literature by emphasising the importance of controlling for multiple adversities. We may assume some psychological mechanisms behind this finding, but because this is the first study that investigated this effect, underlying mechanisms should be investigated in further studies.

Even after rigorously controlling for a broad set of variables, there was at least a threefold increase in lifetime suicide attempt and lifetime suicide ideation among individuals with a history of sexual or physical abuse. These results are consistent with prior studies, ${ }^{26-28}$ but extend this research by providing support for Enns' hypothesis ${ }^{9}$ that childhood sexual abuse may be a risk factor for suicidal behaviour at a relatively young age. To the best of our knowledge, our study is the first to compare the consequences of more violent and bodily intrusive versus less violent childhood adversities in general population samples, controlling for variables that could bias the investigated associations. Sexual or physical abuse were more predictive for lifetime suicide attempt or ideation than other adverse experiences, suggesting that these are uniquely related to attempt and ideation. This underlines the strong negative effects of intrusive experiences in childhood leading to suicidal behaviour across the lifespan. These kinds of experiences may lead to a loss of the positive relationship with one's own body, problematic development of personal identity and psychological integrity; which, in turn, could lead to a wide range of psychological and psychiatric problems, including mental disorders, non-suicidal self-injury and suicidal behaviour. ${ }^{29,30}$ The observed association between aggressive and or intrusive childhood adversities and lifetime suicide attempt and ideation is consonant with the stress-diathesis theory or with the concept of allostatic load: ${ }^{31}$ critical levels of early-life stress may create particular vulnerable conditions for enhanced sensitivity of the hypothalamic-pituitary-adrenal axis, with both biological and emotional consequences. ${ }^{32}$

Given that adolescence and early adulthood are generally seen as periods in which there is a high risk of first-onset suicidal behaviour, ${ }^{3,33}$ and that there are not many studies focusing on the life course of suicide, ${ }^{2}$ our data are important as we found that adversities (and especially sexual and physical abuse) were most predictive of suicidal behaviour in this age group. Our data also suggest a decrease of the influence of adversities on suicide attempts when respondents have reached a certain critical age (i.e. early adulthood), whereas its influence on suicide ideation remains stable, even as people get older. At this point, our data do not allow us to identify which groups of respondents will eventually mature out and which will not. These variations require further investigation.

Only a few adversities predicted suicide persistence, albeit with smaller effect sizes than those between adversities and suicide onset. Sexual and physical abuse were strong risk factors for both onset and persistence of suicidal behaviour. ${ }^{5}$ Furthermore, in contrast with the effect of number of adversities on onset of suicidal behaviour, we found no evidence for sub-additive interaction effects in our analyses on persistence. This suggests that being exposed to multiple adversities increases suicide persistence considerably with each additional adversity experienced.

\section{Implications}

In an era where there is great emphasis on the prevention of suicide worldwide, our data hold some important implications. Earlier studies pointed to the importance of mental disorders as important risk factors. ${ }^{1-3}$ In addition, our results are relevant to suicide attempts in childhood or at a young age because the direct association between adversities and attempt is most prominent then. This is important because suicide attempts are common reasons why people enter professional healthcare. ${ }^{34}$ Our findings add to the wide range of severe behavioural risk factors (i.e. smoking or the use of illicit substances) or chronic somatic conditions (e.g. back or neck pain, obesity, asthma or arthritis) that occur at a greater frequency in individuals with histories of childhood adversities. ${ }^{35}$ Because childhood adversities are so closely related to suicidal behaviour, and particularly in children and teens, gradually more attention may be given to the prevention of these adversities. Universal or selective prevention of childhood adversities appears to be rather difficult because this requires changes at the family and household level. ${ }^{36}$ By contrast, identifying those families at risk may be more suitable and ultimately may decrease the occurrence of suicidal behaviours around the world.

\section{Acknowledgements}

This report was carried out in conjunction with the World Health Organization World Mental Health Survey Initiative. We thank the World Mental Health staff for assistance with instrumentation, fieldwork and data analysis. 
Ronny Bruffaerts, PhD, Koen Demyttenaere, MD, PhD, Department of Psychiatry, University Hospital Gasthuisberg, Leuven, Belgium; Guilherme Borges, MSC, DrSc, Department of Epidemiological Research, Division of Epidemiological and Psychosocial Research, National Institute of Psychiatry (Mexico) \& Metropolitan Autonomous University, Mexico City, Mexico; Josep Maria Haro, MD, MPH, PhD, Parc Sanitari Sant Joan de Déu, Fundació Sant Joan de Déu, CIBER en Salud Mental, Sant Boi de Llobregat (Barcelona), Spain; Wai Tat Chiu, MA, Irving Hwang, MA Department of Health Care Policy, Harvard Medical School, Boston, Massachusetts, USA; Elie G. Karam, MD, St. George Hospital University Medical Center, Balamand University, Faculty of Medicine, Institute for Development, Research, Advocacy \& Applied Care (IDRAAC), Medical Institute for Neuropsychological Disorders (MIND), Beirut, Lebanon; Ronald C. Kessler, PhD, Nancy Sampson, Department of Health Care Policy, Harvard Medical School, Boston, Massachusetts, USA; Jordi Alonso, MD, $\mathrm{MPH}, \mathrm{PhD}$, Health Services Research Unit, Institut Municipal d'Investigació Mèdica (IMIM-Hospital del Mar); CIBER en Epidemiología y Salud Pública (CIBERESP), Barcelona, Spain; Laura Helena Andrade, MD, PhD, Section of Psychiatric Epidemiology- LIM 23 Department and Institute of Psychiatry School of Medicine University of São Paulo São Paulo, Brazil; Matthias Angermeyer, MD, PhD, Center for Public Mental Health, Goesing am Wagram, Austria; Corina Benjet, MD, National Institute of Psychiatry, Mexico City, Mexico; Evelyn Bromet, PhD, Department of Psychiatry, State University of New York at Stony Brook, New York, USA; Giovann de Girolamo, MD, IRCCS Centro S. Giovanni di Dio Fatebenefratelli, Brescia, Italy; Ron de Graaf, PhD, MSc, Netherlands Institute of Mental Health and Addiction, Utrecht, The Netherlands; Silvia Florescu, MD, PhD, Public Health Research and Evidence Based Medicine Department, National School of Public Health and Health Services Management, Bucharest, Romania; Oye Gureje, MD, PhD, FRCPsych, University College Hospital, Ibadan, Nigeria; Itsuko Horiguchi, DDS, PhD, Department of Public Health, Juntendo University School of Medicine, Japan; Chiyi Hu, MD, MPH, Shenzhen Institute of Mental Health \& Shenzhen Kangning Hospital, Shenzhen, People's Republic of China; Viviane Kovess, MD, PhD, EA 4069 Universite Paris Descartes, Paris, France; Daphna Levinson, PhD, Research \& Planning, Menta Health Services Ministry of Health, Jerusalem, Israel; Jose Posada-Villa, MD, U. Javerina, Centro Medico de la Sabana, Bogota, Colombia; Rajesh Sagar, MD, Department of Psychiatry, All India Institute of Medical Sciences, Delhi, India; Kate Scott, PhD, Department of Psychological Medicine, Wellington School of Medicine and Health Sciences, Otago, New Zealand; Adley Tsang, MD, Hong Kong Mood Disorders Center, CUHK, Prince of Wales Hospital, Hong Kong, China; Svetlozar M Vassilev, MD, New Bulgarian University, Sofia, Bulgaria; David R. Williams, MPH, PhD, Professor of Public Health, Department of Society, Human Development, and Health, Harvard School of Public Health, Boston; Matthew K. Nock, PhD, Department of Psychology, Harvard University, Cambridge, Massachusetts, USA

Correspondence: Ronny Bruffaerts, Department of Neurosciences, University Psychiatric Center - Katholieke Universiteit Leuven (UPC-KUL), Herestraat 49, B-3000 Leuven, Belgium. Email: ronny.bruffaerts@med.kuleuven.be

\section{Funding}

These activities were supported by the US National Institute of Mental Health (NIMH R01MH070884, MH077883), the John D. and Catherine T. MacArthur Foundation, the Pfizer Foundation, the US Public Health Service (R13-MH066849, R01-MH069864 and RO DA016558), the Fogarty International Center (FIRCA R03-TW006481), the Pan American Health Organization (PAHO), the Eli Lilly \& Company Foundation, Ortho-McNeil Pharmaceutical, Inc, GlaxoSmithKline and Bristol-Myers Squibb. A complete list Of World Mental Health (WMH) publications can be found at http://www.hcp.med.harvard.edu/ wmh/. The São Paulo Megacity Mental Health Survey is supported by the State of São Paulo Research Foundation (FAPESP) Thematic Project Grant 03/00204-3. The Bulgarian Paulo Research Foundation (FAPESP) Thematic Project Grant 03/00204-3. The Bulgarian
Epidemiological Study of common mental disorders EPIBUL is supported by the Ministry of Health and the National Center for Public Health Protection. The Chinese World Ment Health Survey Initiative is supported by the Pfizer Foundation. The Shenzhen Mental Health Survey is supported by the Shenzhen Bureau of Health and the Shenzhen Bureau of science, Technology, and Information. The Colombian National Study of Mental Health (NSMH) is supported by the Ministry of Social Protection. The ESEMeD project is funded by the European Commission (Contracts QLG5-1999-01042: SANCO 2004123), the Piedmont Region (Italy), Fondo de Investigación Sanitaria, Instituto de Salud Carlos III, Spain (FIS 00/ 0028), Ministerio de Ciencia y Tecnología, Spain (SAF 2000-158-CE), Departament de Salut, Generalitat de Catalunya, Spain, Instituto de Salud Carlos III (CIBER CB06/02/0046, RETICS RD06/0011 REM-TAP) and other local agencies and by an unrestricted educational gran from GlaxoSmithKline. The WMHI was funded by WHO (India) and helped by Dr R Chandrasekaran, JPMER. The Israel National Health Survey is funded by the Ministry of Health with support from the Israel National Institute for Health Policy and Health Services Research and the National Insurance Institute of Israel. The World Mental Health Japan (WMHJ) Survey is supported by the Grant for Research on Psychiatric and Neurologica Diseases and Mental Health (H13-SHOGAl-023, H14-TOKUBETSU-026, H16-KOKORO-013) from the Japan Ministry of Health, Labour and Welfare. The Lebanese National Menta Health Survey (LEBANON) is supported by the Lebanese Ministry of Public Health, the WHO (Lebanon), Fogarty International, Act for Lebanon, anonymous private donations to IDRAAC, Lebanon and unrestricted grants from Janssen Cilag, Eli Lilly, GlaxoSmithKline, Roche and Novartis. The Mexican National Comorbidity Survey (MNCS) is supported by The National Institute of Psychiatry Ramon de la Fuente (INPRFMDIES 4280) and by the National Council on Science and Technology (CONACYT-G30544-H), with supplementa support from PAHO. Te Rau Hinengaro: The New Zealand Mental Health Survey (NZMHS) is supported by the New Zealand Ministry of Health, Alcohol Advisory Council and the Health Research Council. The Nigerian Survey of Mental Health and Wellbeing (NSMHW) is supported by the WHO (Geneva), the WHO (Nigeria) and the Federal Ministry of Health, Abuja, Nigeria. The Romania WMH study projects 'Policies in Mental Health Area' and 'National Study regarding Mental Health and Services Use' were carried out by Nationa School of Public Health \& Health Services Management (former National Institute for
Research \& Development in Health), with technical support of Metro Media Transilvania, the National Institute of Statistics-National Centre for Training in Statistics, SC. Cheyenne Services SRL, Statistics Netherlands and were funded by Ministry of Public Health (former Ministry of Health) with supplemental support of Eli Lilly Romania SRL. The South Africa Stress and Health Study (SASH) is supported by the US NIMH (R01-MH059575) and National Institute of Drug Abuse (NIDA) with supplemental funding from the South African Department of Health and the University of Michigan. The Ukraine Comorbid Mental Disorders during Periods of Social Disruption (CMDPSD) study is funded by the US NIMH (RO1-MH61905). The US National Comorbidity Survey Replication (NCS-R) is supported by the NIMH (U01-MH60220) with supplemental support from NIDA, the Substance Abuse and Mental Health Services Administration (SAMHSA), the Robert Wood Johnson Foundation (RWJF; Grant 044708) and the John W. Alden Trust.

\section{References}

1 Nock MK, Borges G, Bromet EJ, Alonso J, Angermeyer M, Beautrais A, et al. Cross-national prevalence and risk factors for suicidal ideation, plans and attempts. Br J Psychiatry 2008; 192: 98-105.

2 Nock MK, Borges G, Bromet EJ, Cha CB, Kessler RC, Lee S. Suicide and suicidal behaviour. Epidemiol Rev 2008; 30: 133-54.

3 Kessler RC, Borges G, Walters EE. Prevalence of and risk factors for lifetime suicide attempts in the National Comorbidity Survey. Arch Gen Psychiatry 1999; 56: 617-27.

$4 \mathrm{McHolm} A \mathrm{E}$, MacMillan $\mathrm{HL}$, Jamieson $\mathrm{E}$. The relationship between childhood physical abuse and suicidality among depressed women: results from a community sample. Am J Psychiatry 2003; 160: 933-8.

5 Borges G, Angst J, Nock MK, Ruscio AM, Kessler RC. Risk factors for the incidence and persistence of suicide-related outcomes: a 10-year follow-up study using the National Comorbidity Surveys. J Affect Disord 2008; 105: 25-33.

6 Weissman MM, Bland RC, Canino GJ, Greenwald S, Hwu HG, Joyce PR, et al. Prevalence of suicide ideation and suicide attempts in nine countries. Psychol Med 1999; 29: 9-17.

7 Risch N, Herrell R, Lehner T, Liang KY, Eaves L, Hoh J, et al. Interaction between the serotonin transporter gene (5-HTTLPR), stressful life events, and risk of depression: a meta-analysis. JAMA 2009; 301: 2462-71.

8 Lipschitz DS, Winegar RK, Nicolaou AL, Hartnick E, Wolfson M, Southwick SM. Perceived abuse and neglect as risk factors for suicidal behaviour in adolescent inpatients. J Nerv Ment Dis 1999; 187: 32-9.

9 Enns MW, Cox BJ, Afifi TO, De Graaf R, Ten Have M, Sareen J. Childhood adversities and risk for suicidal ideation and attempts: a longitudinal population-based study. Psychol Med 2006; 36: 1769-78.

10 Ystgaard M, Hestetun I, Loeb M, Mehlum L. Is there a specific relationship between childhood sexual and physical abuse and repeated suicidal behaviour? Child Abuse Negl 2004; 28: 863-75.

11 Molnar B, Buka S, Kessler R. Child sexual abuse and subsequent psychopathology: results from the National Comorbidity Survey. Am J Publ Health 2001; 91: 753-60.

12 American Psychiatric Association. Diagnostic and Statistical Manual of Mental Disorders (4th edn) (DSM-IV). APA, 1994.

13 World Bank. Data \& Statistics, Country Groups by Income. World Bank 2009 (http://web.worldbank.org/WBSITE/EXTERNAL/DATASTATISTICS/ 0, contentMDK:20421402 pagePK:64133150 piPK:64133175 theSitePK: $239419,00 . \mathrm{html})$.

14 Heeringa S, Wells JE, Hubbard F, Mneimneh Z, Chiu WT, Sampson N, et al. Sample designs and sampling procedures. In The WHO World Mental Health Surveys: Global Perspectives on the Epidemiology of Mental Disorders (eds RC Kessler \& TB Üstün): 14-32. Cambridge University Press, 2008.

15 Pennell BE, Mneimneh Z, Bowers A, Chardoul S, Wells JE, Viana MC, et al. Implementation of the World Mental Health Surveys. In The WHO World Mental Health Surveys: Global Perspectives on the Epidemiology of Mental Disorders (eds RC Kessler \& TB Üstün): 33-57. Cambridge University Press, 2008.

16 Harkness J, Pennell BE, Villar A, Gebler N, Aguilar-Gaxiola S, Bilgen I. Translation procedures and translation assessment in the World Mental Health Survey Initiative The WHO World Mental Health Surveys: Global Perspectives on the Epidemiology of Mental Disorders (eds RC Kessler \& TB Üstün): 91-113. Cambridge University Press, 2008.

17 Kessler RC, Ustun TB. The World Mental Health (WMH) Survey Initiative Version of the World Health Organization (WHO) Composite International Diagnostic Interview (CIDI). Int J Methods Psychiatr Res 2004; 13: 93-121.

18 Efron B. Logistic regression, survival analysis, and the Kaplan Meier curve. JAMA 1988; 83: 414-25.

19 Allison PD. Survival analysis of backward recurrence times. J Am Stat Assoc 1984; 80: 315-22.

20 Wolter KM. Introduction to Variance Estimation. Springer-Verlag, 1985 
21 Wilsnack SC, Wonderlich SA, Kristjanson AF, Vogeltanz-Holm ND, Wilsnack R. Self-reports of forgetting and remembering childhood sexual abuse in a nationally representative sample of US women. Child Abuse Negl 2002; 26 : 139-147.

22 Hardt J, Rutter M. Validity of adult retrospective reports of adverse childhood experiences: review of the evidence. J Child Psychol Psychiatr 2004; 45: 260-73

23 Nezlek JB, Sorrentino RM, Yasunaga S, Otsubo Y, Allen M, Kouhara S, et al Cross-cultural differences in reactions to daily events as indicators of crosscultural differences in self-construction and affect. J Cross Cult Psychol 2008; 39: 685-702.

24 Kitayama S, Markus HR, Kurokama M. Culture, emotion, and well-being: good feelings in Japan and the United States. Cognition Emotion 2000; 14: 93-124.

25 Dube SR, Anda RF, Felitti VJ, Chapman DP, Williamson DF, Giles WH. Childhood abuse, household dysfunction, and the risk of attempted suicide throughout the life span. Findings from the Adverse Childhood Experiences Study. JAMA 2001; 286: 3089-96.

26 Bebbington PE, Cooper CC, Minot S, Brugha TS, Jenkins R, Meltzer $\mathrm{H}$, et al Suicide attempts, gender, and sexual abuse: data from the 2000 British Psychiatric Morbidity Survey. Am J Psychiatry 2009; 166: 1135-40.

27 Dinwiddie S, Heath AC, Dunne MP, Bucholz KK, Madden PA, Slutske WS, et al. Early sexual abuse and lifetime psychopathology: a co-twin-control study. Psychol Med 2000; 30: 41-52.

28 Kessler RC, Davis CG, Kendler KS. Childhood adversity and adult psychiatric disorder in the US National Comorbidity Survey. Psychol Med 1997; 27: 1101-19.
29 Wenninger K, Heiman JR. Relating body image to psychological and sexual functioning in child sexual abuse survivors. J Trauma Stress 1998; 11 543-62.

30 Nock MK. Why do people hurt themselves? New insights into the nature and function of self-injury. Curr Dir Psychol Sci 2009; 18: 78-83.

31 Anda RF, Felitti VJ, Walker J, Whitfield, CL, Bremner JD, Perry BD, et al. The enduring effects of abuse and related adverse experiences in childhood: a convergence of evidence from neurobiology and epidemiology. Eur Arch Psychiatry Clin Neurosciences 2006; 56: 174-86.

32 Levin HS, Brown SA, Song J, McCauley S, Boake C, Contant C, et al Depression and posttraumatic stress disorder at three months after mild-to-moderate traumatic brain injury. J Clin Exp Neuropsychol 2001; 23 754-69.

33 Roy A. Family history of suicide behaviour and earlier onset of suicidal behaviour. Psychiatr Res 2004; 129: 217-9.

34 Pirkis JE, Burgess PM, Meadows GN, Dunt DR. Suicidal ideation and suicide attempts as predictors of mental health service use. Med J Aust 2001; 175 $542-5$.

35 Von Korff M, Scott K, Gureye O (eds) Mind and Body: Global Perspectives on Mental-Physical Comorbidity. Cambridge University Press, 2009.

36 MacMillan $\mathrm{HL}$, Fleming JE, Trocme $\mathrm{N}$, Boyle, $\mathrm{M}$, Wong, $\mathrm{M}$, Racine, $\mathrm{YA}$, et al. Prevalence of child physical and sexual abuse in the community. Results from the Ontario Health Supplement. JAMA 1997; 278: 131-5. 